\title{
PERSPECTIVISMO, FENOMENOLOGÍA CULTURAL $Y$ ETNOGRAFIAS POSCOLONIALES: INTERVENCIONES EN UN DIÁLOGO SOBRE LAS CORPORALIDADES
}

SILVIA CITRO ${ }^{1}$

UBA/CONICET

MARIANA GÓMEZ ${ }^{2}$

UBA/CONICET

\begin{abstract}
RESUMEN: Proponemos un diálogo intercultural entre la fenomenología cultural y el perspectivismo amerindio. A partir de diversas escenas, analizamos la utilización de los conceptos de "cuerpo-espiritu", "carne" y "amerindios" en tanto categorías existenciales, en el perspectivismo amazónico y en nuestra etnografía en el Chaco argentino, planteando similitudes y diferencias. Examinaremos los alcances y limitaciones de estas categorías y, en especial, la dimensión corporal y experiencial y, por ende histórica, que éstas involucran. Discutiremos cómo el perspectivismo reproduce parte del dualismo cuerpo - espíritu, fundante del pensamiento occidental moderno; asimismo, argumentaremos que las nociones de corporalidad, ser-en-el-mundo y carne, elaboradas en la fenomenología de Merleau-Ponty, desafían este dualismo, mostrándose más adecuadas para comprender no sólo las corporalidades indígenas, sino también las no-indígenas.
\end{abstract}

PALABRAS CLAVE: Perspectivismo; fenomenología cultural; cuerpo; Tobas.

ABSTRACT: We propose an intercultural dialogue between cultural Phenomenology and Amerindian Perspectivism. Through different scenes we analyze the use of concepts like "bodyspirit", "flesh" and "amerindians" as existentialist categories in the Amazonic Perspectivism and in our own ethnography in the Argentinean Chaco, bringing up similarities and differences. We will examine the scope and limitations of these categories and, especially, the body and experiential -hence historical- dimension they involve. We will discuss how Perspectivism reproduces a body-spirit dualism that belongs to Western modern thinking. In addition, we will argue that the notions of corporality, being in- the world and flesh elaborated in the phenomenology of Merleau- Ponty challenge this dualism, which makes them more appropriate to understand not only the indigenous corporalities, but also the non indigenous ones.

KEYWORDS: Perspectivism; cultural phenomenology; body; Tobas.

\footnotetext{
${ }^{1}$ Dra. en Antropología por la Universidad de Buenos Aires. En la Facultad de Filosofía y Letras de la misma Universidad, se desempeña como investigadora adjunta del CONICET y coordinadora del Equipo de Antropología del Cuerpo y la Performance (www.antropologiadelcuerpo.com) y es también Profesora Adjunta en las carreras de Antropología y Artes. E-mail: scitro_ar@yahoo.com.ar .

${ }_{2}^{2}$ Dra. en antropología. UBA-Facultad de Filosofía y Letras. Sección Etnología y Etnografía. Becaria Postdoctoral del CONICET. E-mail: gomin19@yahoo.com.
}

Espaço Ameríndio, Porto Alegre, v. 7, n. 1, p. 253-286, jan./jun. 2013. 
SILVIA CITRO y MARIANA GÓMEZ - Perspectivismo, fenomenología cultural...

Nuestra intención es proponer un diálogo intercultural sobre las corporalidades indígenas y no indígenas, convocando diversas voces: fundamentalmente ciertos planteos del perspectivismo de Viveiros de Castro y de la fenomenología de Merleau-Ponty, los cuales serán releídos desde nuestra experiencia etnográfica con las y los indígenas tobas de Formosa, Argentina, así como desde una etnografía clásica sobre el tema, como ha sido Do Kamo de Maurice Leenhardt, sobre los canacos de Melanesia.

Para comenzar, situaremos brevemente algunas de las posiciones geopolíticas y genealogías teóricas desde las cuales partimos. Para una parte de los antropólogos argentinos que trabajamos con grupos indígenas, la región Chaqueña podría ser una de las áreas más similares a la Amazonía, al menos en lo que refiere a la importancia de las tradiciones cazadoras-recolectoras, de la división del trabajo por géneros (GÓMEZ, 2008a, 2009 y 2011), la reciprocidad (GORDILLO, 1992, 1994 y 2004) y de las guerras intertribales del pasado (MENDOZA, 2002), la persistencia del chamanismo, de ciertas creencias y estructuras míticas compartidas (LEVI-STRAUSS, 1986; TOLA, 2012) o incluso de sus expresiones rituales musicales (MENEZES BASTOS, 2007; CITRO y CERLETTI, 2009). No obstante estas similitudes se aprecian diferencias respecto al ambiente ecológico que habitan estos pueblos ${ }^{3}$, sus sistemas de parentesco y organización social, y en la importancia atribuida a las transformaciones históricas, especialmente desde el período postcolonial hasta la actualidad.

En el caso chaqueño estos cambios se vinculan al impacto de las campañas militares del ejército nacional desde fines del siglo XIX hasta las dos primeras décadas del XX; los intensos procesos de misionalización protestante (desde la década del ' 10 con los anglicanos $y$ del '40 con los pentecostales y menonitas) $y$, en menor medida,

\footnotetext{
${ }^{3}$ El Chaco es una región árida, rodeada en sus límites por los ríos Paraguay, Paraná y el Salado. En su interior corren los ríos Bermejo y Pilcomayo y también hay lagunas, aguadas y bañados; sin embargo, la escasez de agua es una característica de la región que en el pasado obligaba a que los grupos nomadicen y muevan sus campamentos en función de este recurso vital. El ciclo económico de los grupos del Chaco tenía períodos de escasez (invierno-primavera) y abundancia de pescado y frutos del monte durante el verano. El control de los sitios que tenían agua y recursos era uno de los principales motivos que intervenían en las guerras intertribales.
} 
SILVIA CITRO y MARIANA GÓMEZ - Perspectivismo, fenomenología cultural...

católicos en algunas pocas comunidades (CORDEU y SIFFREDI, 1971; MILLER, 1979; WRIGHT, 1997; CITRO, 2003 e 2009, CERIANI CERNADAS, 2008); las transformaciones de las relaciones de producción a partir del comercio y el trabajo asalariado en ingenios azucareros (GORDILLO, 1992; LAGOS, 2000; GÓMEZ, 2011), explotaciones forestales y plantaciones. Asimismo, especialmente desde mediados del siglo XX, la presencia y acción estatal reforzó las prácticas y lógicas "civilizatorias" conducidas por las misiones en las décadas anteriores (como la escolarización, higiene y medicina occidental) e introdujo nuevas prácticas legales-burocráticas (como los documentos de identidad, títulos de propiedad de la tierra, jubilaciones y planes asistenciales, etc.) y, ya con el retorno de la democracia a inicios de la década de 1980, la política partidaria y las elecciones (WRIGHT, 1997; GORDILLO, 2002, 2004; CITRO, 2003; CARDIN, 2007). Todo ello nos lleva a otorgar una particular importancia a la relación entre estos procesos históricos y los cambios socio-culturales, a los vínculos con el estado y la economía política, incluso para aquellos que trabajamos en temáticas como el ritual, el arte y las prácticas y representaciones corporales, como es el caso de Citro, o las relaciones de género y los usos del territorio, como es el de Gómez 4 . Sin embargo, si nos guiamos por los últimos escritos de Viveiros de Castro (2004 e 2010), así como por los de algunos otros colegas que acompañaron y siguieron sus lineamientos, notamos la ausencia de referencias a estos procesos, por ello nos preguntamos si los grupos amazónicos fueron menos afectados por este tipo de dinámicas o éstas tuvieron un impacto menor en la transformación de las subjetividades y corporalidades indígenas. En este sentido, recientemente Alcida Ramos ha señalado que el perspectivismo reduce la complejidad etnográfica de "Amazonia" a un único modelo, llevando a que las etnografías locales arrojen resultados uniformes que tienden a tomar la forma de un dogma. La autora sostiene que "Amazonia" no es una región homogénea culturalmente y que el perspectivismo no toma en cuenta ni las problemáticas históricas ni las actuales que afectan "las vidas reales de los indígenas" (RAMOS, 2012, p. 482).

\footnotetext{
${ }^{4}$ Citro ha trabajado estas temáticas con los tobas del este de Formosa, mientras que Gómez con los del oeste de la misma provincia. Ambos grupos muestran fuertes vínculos históricos y culturales, pero representan dos parcialidades distintas con dialectos diferentes $\mathrm{y}$, además, han vivido distintos procesos de conversión religiosa.
} 
SILVIA CITRO y MARIANA GÓMEZ - Perspectivismo, fenomenología cultural...

Probablemente en este peso diferencial otorgado a los cambios históricos incidan las genealogías y trayectorias intelectuales de los autores. Es conocida la importante influencia de la etnología francesa y en especial de aquella de inspiración estructuralista, y más recientemente, de autores posestructuralistas como Deleuze en el perspectivismo amazónico. En cambio, como iremos viendo, en nuestro caso particular reconocemos una influencia mayor del marxismo, de ciertas líneas de la antropología norteamericana (como la antropología de la experiencia de Turner, la fenomenología cultural de Csordas) e incluso de otras antropologías latinoamericanas como la mexicana y, si bien hay también importantes influencias francesas, se centran en otras corrientes teóricas: la fenomenología existencialista de Sartre y Merleau-Ponty, la hermenéutica de Ricoeur, el pensamiento de Foucault y el de Bourdieu.

Por otra parte, la historia política reciente de la Argentina incidió en la formación antropológica, concretamente a través del recambio de docentes e investigadores durante la última dictadura y luego con el retorno de la democracia, generando tensiones y disputas al interior del campo académico. Si bien se trata de un tema complejo y que sólo en los últimos años ha comenzado a ser profundizado (TISCORNIA y GOLLIER, 1984; GORDILLO, 2006; PERAZZI, 2003), nos interesa destacar aquí que durante las décadas del ' 70 e inicios de los ` 80 , la región chaqueña fue particularmente sitio de estas disputas teóricas: entre una peculiar versión de la fenomenología husserliana, centrada en el análisis mitológico y cosmovisional del mundo y la "conciencia" indígena, que fue hegemónica durante la dictadura (BÓRMIDA,1969) y los trabajos de las nuevas generaciones de antropólogos que les siguieron, ligados primero a los estudios sobre mesianismo y cambios socio religiosos (CORDEU y SIFFREDI, 1971) y luego también a la antropología social, el marxismo y la antropología económica (HERMITTE et al 1995; TRINCHERO, PICCININI y GORDILLO, 1992; GORDILLO, 1992). Sin embargo, especialmente a partir de la década del ' 90 , surgieron etnografías que complejizaron el abordaje de los pueblos chaqueños al combinar algunas de las perspectivas teóricas antes mencionadas (WRIGHT, 2008; GARCÍA, 2005; CITRO, 2003; GORDILLO, 2004; CERIANI CERNADAS, 2008; GÓMEZ, 2011). La necesidad de trascender los límites 
SILVIA CITRO y MARIANA GÓMEZ - Perspectivismo, fenomenología cultural...

impuestos por dicotomías que muchas veces oponían economía política y mundo mítico, determinación económica y cosmovisional, marxismo y fenomenología, nos condujo a abrir nuestro horizonte teóricometodológico a diversas perspectivas y a efectuar una etnografía en cierta forma más ecléctica.

A partir de varias escenas y diálogos basados en nuestra experiencia etnográfica y en las genealogías teóricas señaladas, analizaremos la utilización de los conceptos de "cuerpo-espíritu", "carne" y "amerindios" en tanto categorías existenciales en el perspectivismo amazónico y en nuestra etnografía en el Chaco, planteando algunas de las similitudes y diferencias que encontramos. Nuestra intención es poder discutir los alcances y limitaciones de estas categorías y, en especial, la dimensión corporal y experiencial y, por ende histórica, que éstas involucran.

\section{Primer diálogo existencial: “Todos somos un espíritu...”}

Comenzaremos con un fragmento del diálogo que Silvia mantuvo en un trabajo de campo con Hilaria, miembro de la "Comunidad Aborigen La Primavera", en 1998. En esa época, Hilaria era una joven dirigente política vinculada al peronismo (al que también pertenecía su padre), "tesorera" y cantante "solista" en la Iglesia Evangélica Unida, a la vez que madre de dos hijas pequeñas, es decir, una mujer indígena con diversas posiciones identitarias.

Cabe aclarar que el vínculo de estos grupos tobas con el peronismo se fundamentaba especialmente en la memoria histórica que fue transmitida de generación en generación sobre el primer gobierno de J. D. Perón (1945-1955), donde se favoreció un proceso de inclusión ciudadana que les permitió acceder a documentos de identidad, participar de elecciones y obtener la propiedad legal de algunos territorios. Por otra parte, la Iglesia Evangélica Unida fue la primera iglesia indígena de la Argentina y junto con otras denominaciones constituyó el movimiento denominado "Evangelio", resultado de la interacción entre la religiosidad pentecostal traída por los misioneros blancos y las tradiciones tobas, junto con la asistencia de los menonitas 
SILVIA CITRO y MARIANA GÓMEZ - Perspectivismo, fenomenología cultural...

(MILLER, 1979; WRIGHT, 1997)5.

Una noche, luego de la cena, estábamos conversando con Hilaria en su casa y surgió el tema de los diferentes seres no humanos poderosos o jaqa'a, y en especial sobre pe 'lek, habitante de la noche, a quien conocíamos gracias a los trabajos anteriores de Pablo Wright (1997).

Silvia: ¿El pel 'ek es como un habitante de la noche, no? Hilaria: Si, sería igual que nosotros, pero de noche nomás.

S: Y un pel'ek ¿sería ÿaqa'a [ser no humano poderoso]?

$\mathrm{H}$ : También, sería (...) hay pel'ek uno dice que es su compañero, otro que te trae mala suerte, otro que te protege, otro que te ayuda (...). Supongamos, si vos querés tener un guardián, vos mismo podés preguntar, podés llamar, entonces vos misma estás aceptando ¿Ahora en Buenos Aires no sé si existen o no...?

S: Y... yo nunca vi... [riendo].

$\mathrm{H}$ : Tenés que llevar uno... [riendo] (...).

S: ¿Pero los pel'ek tienen que ver con espíritus o... son como una especie de...?

$\mathrm{H}$ : $\mathrm{Si}$, son espíritus también, porque creo que todos somos un espíritu, entonces vendría a ser que ellos son un espíritu, yo soy un espíritu y los ÿaqa'a son un espíritu, hasta tal vez ellos cuando nos ven nos tienen miedo...

S: Claro, hay que ver que somos para ellos... ¿no?

$\mathrm{H}$ : Tal vez somos semejantes...

Cuando surgía este tipo de diálogos siempre reaparecían nuestros interrogantes sobre la condición ontológica de estos seres no humanos poderosos. La categoría de "espíritu", con la inmaterialidad que conlleva en la tradición de la modernidad occidental, resultaba limitada para caracterizar a muchos de estos seres que algunos qom veían, olían o con los que incluso podían dialogar. Se diferencian de los humanos por el peculiar "poder" que poseen pero se los concibe con rasgos semejantes. De ahí que Hilaria acepte la denominación de "espíritu" que la antropóloga enuncia, aunque sólo a condición de pensar que "todos somos un espíritu" y "tal vez somos semejantes", y que así como los

\footnotetext{
5 El Evangelio se ha convertido así en la religión dominante en estos grupos y actualmente sus celebraciones son los únicos rituales colectivos vigentes (WRIGHT, 2008; CITRO, 2003 y 2009).
}

Espaço Ameríndio, Porto Alegre, v. 7, n. 1, p. 253-286, jan./jun. 2013. 
SILVIA CITRO y MARIANA GÓMEZ - Perspectivismo, fenomenología cultural...

humanos temen de los pe'lek tal vez ellos también teman cuando ven a los humanos.

Estas definiciones de Hilaria fácilmente encajarían con aquello que, a partir de mediados de los '90, Viveiros de Castro y Stolze Lima denominaron "perspectivismo amerindio", en tanto "concepción", "ontología", "pensamiento" o "filosofía" según la cual el mundo está habitado por diferentes especies de sujetos o personas, humanas y no humanas, que lo aprehenden desde puntos de vista distintos; pero estos puntos de vista no son meras representaciones, en tanto "propiedades del espíritu", sino que el "punto de vista está en el cuerpo" (VIVEIROS DE CASTRO, 2004, p. 56). Así, para el autor, los pueblos del Nuevo Mundo

comparten una concepción según la cual el mundo está compuesto por una multiplicidad de puntos de vista: todos los existentes son centros de intencionalidad, que aprehenden a los otros existentes según sus respectivas características y capacidades (VIVEIROS DE CASTRO, 2010, p. 33).

Este perspectivismo en el que humanos $y$ no humanos interaccionan como "agentes" con intencionalidades diferenciales, encuentra su fundamento en la mitología amerindia. Vayamos entonces a un segundo diálogo sobre este tema.

Segundo diálogo: nuestros mitos son "casi igual que los científicos..."

En 1999, al año de su primer trabajo de campo, Silvia recibió en Buenos Aires la visita de Teresa y su esposo Vicente, con quienes convivió por 10 días en su casa, un pequeño departamento de la ciudad de Buenos Aires (CITRO, 2002). Ambos eran oriundos de Misión Taccaglé, una comunidad ubicada a $100 \mathrm{~km}$ de La Primavera donde poseían lazos de parentesco, de hecho Teresa era hermana, por parte de madre, de Hilaria. Teresa en ese momento tenía unos 60 años, era artesana, conocedora de muchas "historias antiguas" o "cuentos", como los tobas suelen llamar a los mitos, y además, una ferviente creyente en el Evangelio, con cierto poder de "sanación" a través de la oración. Una de las noches en Buenos Aires, Teresa comenzó a recordar algunos de 
SILVIA CITRO y MARIANA GÓMEZ - Perspectivismo, fenomenología cultural...

sus cuentos. Primero contó el mito del origen de las mujeres y los hombres (que incluye el conocido motivo de "la vagina dentada") y lo vinculó con el origen de la mujer en la Biblia. Luego preguntó si nosotros, los "blancos", teníamos "algún cuento sobre el origen de las personas", y entonces Silvia hizo referencia a Darwin y su teoría sobre el origen de las especies, uno de nuestros "cuentos" favoritos. A partir de este comentario, Teresa le recordó otro mito toba que, fiel a su usual estilo comparativo, le parecía "casi igual" al de los científicos. Este mito refiere a uno de los cataclismos de renovación del mundo en el que "la gente" sobrevivió escondida bajo la tierra (incluso lo comparó con "el subte", en el que había viajado unos días atrás), sólo con la diferencia de que a medida que algunas de estas personas fueron saliendo a la superficie, se convertían en animales, originando las diversas especies. Así, dentro de este horizonte mítico que otorga un origen común a esa "gente", que luego se diferenciará en humanos y animales, estos últimos hoy siguen "ofrendando" su alimento a los humanos y brindándoles diversas "señas".

Teresa: Esa historia antigua, TODO, casi son igual que los científicos. En el principio también se cuenta así... dijo un cuento también, cuando la gente le hicieron, la historia no sé de dónde viene pero yo me enteré que es cuento, dijo que en el principio, las mujeres, los hombres y los chicos, se transforma todo, pero pongamos en subte, se va abajo...

Silvia: Ah, como el subte que fuimos el otro día...

$\mathrm{T}$ : Y después cuando salieron la gente, salieron de las cuevas, lo que mira del campo ya se transforma (...). Hay persona que dijo que no tiene que mirar en el campo, sino te va a transformar animal (...) por ejemplo oso hormiguero es una vieja y después dijo que al salir de la cueva mira el monte, se transforma ya en oso hormiguero, TODA COSA se transforma.

S: Es parecido al de Darwin pero al revés, de persona pasa a ser animal...

T: Si, el guasuncho dice que una señorita $\operatorname{LINDA}(\ldots)$. Ñandú un hombre también, se transforma, y después dijo que esa es una seña para la gente aborigen, la seña que en ese momento nosotros no falte alimento (...) ellos parece que le ofrendó su vida para que le ocupan los que mariscan [cazan].

Al comparar la ontología que deriva del mito toba y de la teoría 
SILVIA CITRO y MARIANA GÓMEZ - Perspectivismo, fenomenología cultural...

darwiniana, encontramos que en la primera se trata de una condición existencial compartida en el tiempo mítico, y tanto animales como seres humanos surgirán luego de transgresiones a esa condición inicial común: los animales surgen de violar la prohibición de salir de las cuevas y la humanidad surge de la transgresión de sus espacios y condiciones primigenias, pues como se plantea en el mito de origen de las mujeres, las poderosas mujeres del cielo bajaban a robarle el alimento a los poderosos hombres-animales de la tierra ${ }^{6}$. En la ontología inspirada en la teoría darwiniana clásica, en cambio, el ser humano era la superación, en términos evolutivos, de una condición animal originaria. Así, también en este ejercicio comparativo que iniciamos con Teresa años atrás se comprueba aquello que Viveiros de Castro plantea para el pensamiento amerindio en general: "La condición original común a humanos y animales no es la animalidad, sino la humanidad", a diferencia de "nuestra mitología evolucionista moderna", donde existe una "diferenciación de lo humano a partir de lo animal" (VIVEIROS DE CASTRO, 2004, p. 41). No obstante, una diferencia que persiste es que a Teresa ambas mitologías le parecían casi "iguales" mientras que Viveiros de Castro remarca los contrastes. De hecho, encontramos que a partir de sus reflexiones sobre el material amazónico y algunas anécdotas extraídas de Levi Strauss, el autor alcanza la conclusión de que para los amerindios, entre humanos y nohumanos existiría "una unidad del espíritu y una diversidad de los cuerpos" (VIVEIROS DE CASTRO, 2004, p. 34). Esta teoría representaría la inversión de la oposición prevaleciente en la perspectiva moderna, en la cual habría una "diversidad del espíritu y una unidad de los cuerpos", e incluso de la misma oposición levistraussiana entre naturaleza y cultura, pues aquí la cultura sería la forma que asume lo "universal" mientras que la "naturaleza", es decir, las corporalidades, la forma de lo particular. Como aclara en uno de sus textos:

Nuestra cosmología imagina una continuidad física y una discontinuidad metafísica entre los humanos y los animales, (...). El espíritu es nuestro gran diferenciador. (...) El cuerpo, al contrario, es el gran integrador, el vehículo de la "participación moderna": lo

\footnotetext{
${ }^{6}$ Para un análisis de este mito y otros vinculados puede verse, Tola (2008), Citro (2008) y Gómez (2008a).
} 
SILVIA CITRO y MARIANA GÓMEZ - Perspectivismo, fenomenología cultural...

que nos conecta al resto de los seres vivos (...). Los amerindios, en contrapartida, imaginan una continuidad metafísica y una discontinuidad física entre los seres del cosmos (VIVEIROS DE CASTRO, 2004, p. 57).

En suma, el pensamiento perspectivista, en tanto modelo elaborado a partir de considerar los "problemas filosóficos planteados por el pensamiento indígena" (VIVEIROS DE CASTRO, 2010, p. 35), parece organizarse sobre una lógica de oposiciones binarias en torno al cuerpo y al espíritu, entre ellos (los "amerindios") y nosotros (los supuestos "modernos", aunque no queda muy claro a quienes se pretende representar con esta categoría, si a los "antropólogos", los "científicos", la "ciencia", etc.). El siguiente cuadro sintetiza estas oposiciones:

\begin{tabular}{|l|c|c|}
\hline \multirow{3}{*}{ ESPIRITU } & AMERINDIOS & MODERNOS \\
& $\begin{array}{c}\text { Unidad } \\
\text { Continuidad metafísica } \\
\text { Integrador }\end{array}$ & $\begin{array}{c}\text { Diversidad } \\
\text { Discontinuidad metafísica } \\
\text { Diferenciador }\end{array}$ \\
\hline \multirow{2}{*}{ CUERPO } & $\begin{array}{c}\text { Diversidad } \\
\text { Discontinuidad física } \\
\text { Diferenciador }\end{array}$ & $\begin{array}{c}\text { Unidad } \\
\text { Continuidad física } \\
\text { Integrador }\end{array}$ \\
\hline
\end{tabular}

Cuadro 1. Categorías de cuerpo-espíritu en amerindios y modernos.

Nuestra propia experiencia etnográfica y los trabajos anteriores con los tobas nos persuadieron de que existía una continuidad o comunión ontológica entre seres humanos y no-humanos ${ }^{7}$ que, vista en estos términos, contrasta con la ontología racionalista de aquellos supuestos "sujetos modernos" en torno a la "naturaleza" o, más precisamente, con el pensamiento hegemónico en las ideologías de la modernidad. No obstante, a pesar de que los y las tobas se representan y experimentan dicha continuidad, especialmente en su relación con el monte a través de la caza, pesca y recolección o en el chamanismo, estas ontologías y prácticas indígenas se articulan de manera pragmática y dialéctica con

\footnotetext{
7 O entre "naturaleza" y "cultura", si nos remitimos a los trabajos de Descola (2001); ver también Gómez, (2008a).
} 
SILVIA CITRO y MARIANA GÓMEZ - Perspectivismo, fenomenología cultural...

las de la modernidad, que en el Chaco se vieron encarnadas principalmente en las nuevas disciplinas impuestas por las misiones, el mercado y el estado (GORDILLO, 2004; GÓMEZ, 2008a).

Por otra parte, como propuso Citro (2009) y retomaremos más adelante, una experiencia holística en la relación "cuerpo-mundo" o "naturaleza-cultura" basada en la fluidez de los lazos entre lo humano, lo animal y lo no-humano, no sería exclusiva de los indígenas amerindios, pues también fueron comunes, por ejemplo, en Europa occidental antes de iniciarse el "proceso civilizatorio" (ELÍAS, 1993) y de racionalización del cuerpo y de la vida que acompañó el desarrollo capitalista.

Finalmente, señalamos que, si el proyecto de Viveiros de Castro apunta a contrastar aquella "filosofía indígena" o "presuposición antropomórfica del mundo indígena" que se opondría al "esfuerzo antropocéntrico de la filosofía occidental" (VIVEIROS DE CASTRO, 2010, p. 44$)^{8}$, cabe recordar que dentro de esta última existieron voces diversas que también confrontaron esas ideas hegemónicas de la modernidad. Tal es el caso de ciertas tradiciones alemanas en Hegel, Nietzsche e incluso en los últimos escritos de Freud ${ }^{9}$, influencias que, junto a las de autores como Leibniz, Whitehead y Deleuze, actúan incluso como referentes para el mismo perspectivismo (VIVEIROS DE CASTRO, 2010, p. 33). Asimismo, recordamos que durante las últimas décadas esta escisión ontológica entre una naturaleza despojada de intencionalidades y la humanidad como única detentora de voluntad y reflexión, ha sido cuestionada en otros ámbitos: desde el florecimiento de pensamientos filosóficos y religiosos de raíz oriental difundidos con la new age, los discursos ecologistas, hasta ciertos desarrollos científicos recientes en las ciencias naturales y físicas que se inspiran en paradigmas de las ciencias de la cultura para pensar el mundo físico y biológico (DE SOUSA SANTOS, 2009, p. 41 ).

En suma, aún considerando estas contrahegemonías, es claro que esta continuidad ontológica entre lo humano y no-humano define una

\footnotetext{
${ }^{8}$ Aunque es pertinente señalar que ningún filósofo o intelectual del movimiento indígena latinoamericano ha sido invitado a participar en este "debate" que pretende dar el autor.

${ }^{9}$ En otros trabajos (CITRO, 2003 e 2009), analizamos cómo en estos autores se aprecia el intento de buscar principios que ligaran la corporalidad, los deseos y pasiones del mundo humano con la naturaleza, intentando identificar una lógica común.
} 
SILVIA CITRO y MARIANA GÓMEZ - Perspectivismo, fenomenología cultural...

de las principales diferencias entre las cosmovisiones amerindias de las "tierras bajas" y la "ideología" hegemónica de la modernidad. Sin embargo, tenemos dudas respecto a la oposición entre cuerpo y espíritu en la que se asientan los escritos de Viveiros de Castro, porque además de ser el eje articulador dentro del concepto de "multinaturalismo", a partir de nuestras experiencias etnográficas nunca habíamos pensado a las corporalidades tobas sólo como exclusivamente "diferenciadoras" en oposición a nuestra supuesta idea del cuerpo como gran "integrador". Más bien tendíamos a imaginar que integración y diferenciación eran parte de los devenires experienciales del cuerpo, de todos nosotros, aunque con sus propias formas culturales.

\section{Tercer diálogo: el cuerpo y el espíritu en el perspectivismo y en la etnografía toba.}

Veamos con más detalle cómo Viveiros de Castro define al cuerpo y al espíritu en algunas de sus obras. Ya en su artículo con Seeger y Da Matta se insistía en la importancia de las corporalidades pues se proponía abordar "la socio-lógica indígena a partir de una fisio-lógica" (SEEGER, DA MATTA y VIVEIROS DE CASTRO, 1979, p. 13), en tanto en estas sociedades, el lenguaje simbólico de la persona (a través del tratamiento corporal, las concepciones sobre la gestación, los fluidos corporales, los nombres, entre otros) sería más rico que el lenguaje provisto por los grupos sociales. Si bien aquí pueden rastrearse conexiones con lo que luego se denominó la perspectiva fenomenológica del embodiment, según Viveiros de Castro dicho texto no fue escrito en vinculación con esas ideas ${ }^{10}$. Por otra parte, en su reciente libro Metáforas Caníbales, el autor utiliza conceptos como "multiplicidades sensibles", "devenires animales", "flujos orgánicos y codificaciones materiales" (VIVEIROS DE CASTRO, 2010, p. 32)

\footnotetext{
${ }^{10}$ Incluso se refiere en términos irónicos a esa corriente “...que iba a tomar por asalto a la antropología en las décadas siguientes. La corriente estructuralista de la etnología amerindia, sorda al llamado "piadoso y sensual a la vez" del carnismo fenomenológico (DELEUZE y GUATTARI, 1991, p. 169) -el "atractivo de la madera podrida", diría un lector de Lo crudo y lo cocido- siempre ha pensado la encarnación desde el punto de vista del triángulo culinario antes que el de la Santísima Trinidad" (VIVEIROS DE CASTRO, 2010, p. 33).
} 
SILVIA CITRO y MARIANA GÓMEZ - Perspectivismo, fenomenología cultural...

denotando las influencias de Deleuze y el postestructuralismo; asimismo, a partir del uso del término "habitus" (VIVEIROS DE CASTRO, 2010 , p. 55), también nos preguntamos por la posible incidencia de la fenomenología de Merleau-Ponty y la obra de Bourdieu, aunque no se cite a estos autores. No obstante, notamos que por detrás de esta experiencia que se supone fluida e indeterminada continúa operando una estructura binaria de oposición entre "espíritu" y "cuerpo" que, además, actúa como una oposición privilegiada que articula gran parte de su modelo teórico. Si entendemos que las experiencias corporales indígenas son -ontológicamente hablando- fluidas y mutables: ¿No deberíamos reconsiderar nuestras ideas e imaginarios sobre la estructura del orden simbólico para no reproducir aquellos dualismos epistemológicos que Viveiros de Castro también critica? Veamos con más detalle cómo se definen estas categorías de cuerpo-espíritu en el pensamiento amerindio:

\begin{tabular}{|c|c|}
\hline CUERPO & ESPÍRITU \\
\hline $\begin{array}{l}\text { "no es una fisiología distintiva o una } \\
\text { anatomía característica, es un conjunto de } \\
\text { maneras y modos de ser que constituyen un } \\
\text { habitus, un ethos, un ethograma" } \\
\text { (VIVEIROS DE CASTRO, 2010, p. 55). } \\
\text { "haz de afectos y capacidades" (VIVEIROS } \\
\text { DE CASTRO, 2010, p. 55). }\end{array}$ & 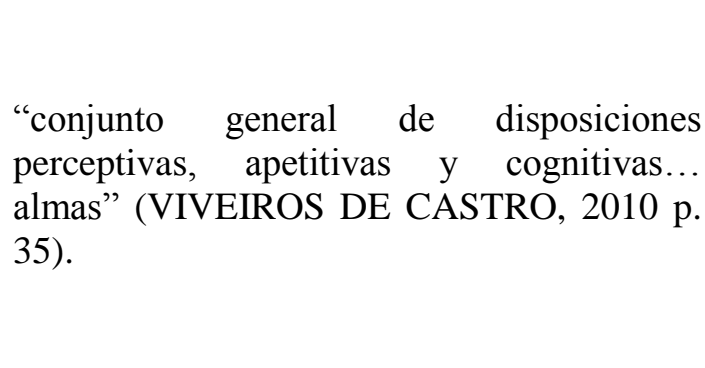 \\
\hline $\begin{array}{l}\text { "no es sustancia material" (VIVEIROS DE } \\
\text { CASTRO, 2004, p. 57). }\end{array}$ & $\begin{array}{l}\text { "no es sustancia inmaterial" (VIVEIROS } \\
\text { DE CASTRO, 2004, p. 57). }\end{array}$ \\
\hline $\begin{array}{l}\text { "es inclinación activa" (VIVEIROS DE } \\
\text { CASTRO, 2004, p. 57). }\end{array}$ & $\begin{array}{l}\text { "es forma reflexiva" (VIVEIROS DE } \\
\text { CASTRO, 2004, p. 57). }\end{array}$ \\
\hline $\begin{array}{l}\text { "gran diferenciador (...), las categorías de } \\
\text { identidad -individuales, colectivas, étnicas } \\
\text { o cosmológicas- se expresan tan } \\
\text { frecuentemente por medio de idiomas } \\
\text { corporales, en particular a través de la } \\
\text { alimentación y del adorno corporal" } \\
\text { (VIVEIROS DE CASTRO, 2004, p. 61). }\end{array}$ & $\begin{array}{l}\text { "unidad del espíritu" (op.cit. } 34 \text { ), } \\
\text { "continuidad metafísica" (VIVEIROS DE } \\
\text { CASTRO, 2004, p. 57). }\end{array}$ \\
\hline
\end{tabular}

Cuadro 2. Definiciones de cuerpo y espíritu en el pensamiento amerindio, según Viveiros de Castro.

Espaço Ameríndio, Porto Alegre, v. 7, n. 1, p. 253-286, jan./jun. 2013. 
SILVIA CITRO y MARIANA GÓMEZ - Perspectivismo, fenomenología cultural...

Si intentamos seguir la reflexión perspectivista para comprender el caso toba, reconoceríamos que, por ejemplo, un humano, un pelek y un animal, poseen una intencionalidad semejante, legitimada en el corpus mítico, que se encarnaría en formas o morfologías corporales visiblemente diferentes, en "maneras y modos de ser" disímiles, y que en este "haz de afectos y de capacidades", que sería el cuerpo, se fundan las distintas perspectivas o "puntos de vista". No obstante estos acuerdos generales nos surgieron varias preguntas respecto de estas definiciones. En primer lugar, que el cuerpo sea utilizado para construir "distinciones identitarias" -especialmente a través del adorno corporal, la alimentación o el habitus-, no parece privativo de los pueblos amazónicos o chaqueños, pues esto se aprecia, con sus propias formas, en diferentes sociedades y períodos históricos (MELLOR y SCHILLING, 1997).

En segundo lugar, cabe preguntarse si sólo existen "diferencias" entre estos supuestos cuerpos. Si, por ejemplo, reconocemos con el autor que humanos y no humanos están dotados todos de un mismo conjunto de disposiciones perceptivas, apetitivas y cognitivas, o dicho de otro modo, de "almas semejantes", ¿Por qué no considerar que, al menos, percepción y apetito o deseo son también disposiciones de aquello que los occidentales modernos tradicionalmente llamaron "cuerpo" y, justamente, no solo diferencian a humanos y no humanos sino que también los asemejarían? ¿El "haz de afectos y capacidades" que sería el cuerpo hasta qué punto se diferencia tanto de aquellas "disposiciones perceptivas, apetitivas y cognitivas" que sería el alma? ¿No se están superponiendo aquí los términos de cuerpo y espíritu? ¿La "inclinación activa" que sería el cuerpo no implica acaso la intervención de la "forma reflexiva" que sería el alma? Si el cuerpo "no es una sustancia material" ¿dónde se encarnan sus "inclinaciones activas", su agentividad? Y si el espíritu "no es una sustancia inmaterial” ¿No sería alguna clase de cuerpo entonces...?. Lo que queremos plantear con estas múltiples preguntas es que estas categorías, aunque redefinidas por el autor, son dualistas e insuficientemente claras para pensar estas "ontologías amerindias", y mas aún, para ser erigidas como los términos privilegiados para una comparación con la ontología moderna. 
SILVIA CITRO y MARIANA GÓMEZ - Perspectivismo, fenomenología cultural...

La tercera cuestión a problematizar es que "los puntos de vista" encarnados en cuerpos con habitus disímiles que señala el perspectivismo no producen entre los tobas, ni probablemente entre otros "amerindios", cuerpos individuales que se conciben como más o menos independientes entre sí, al estilo de la ideología de la modernidad, sino que estos seres suelen estar material y reflexivamente interconectados, estrechamente vinculados a través de intercambios de alimentos y flujos corporales, del significado otorgado a las percepciones y a las sensaciones corporales, a las señas de los nohumanos, de los sueños y los pensamientos. Diríamos entonces que humanos y no humanos participan de una misma red existencial y justamente las sensaciones-emociones corporales (especialmente el dolor-enfermedad-tristeza y la fortaleza-salud-alegría) serían uno de los índices más visibles de estas múltiples relaciones entre los seres del mundo. Especialmente la experiencia toba del contagio o nawoGa, muestra la importancia de estos vínculos. Diversos elementos provenientes de animales y plantas implican formas de nawoGa o de "contagiar" a la persona una característica de ese elemento. En el pasado existían una serie de contagios positivos vinculados a las prácticas de caza y recolección, tal es el caso de las escarificaciones con huesos de animales, denominadas nqana, que "contagiaban" a los cazadores las cualidades de un animal. Por ejemplo, el nqana de chancho morito hacía que, al igual que dicho animal, la persona "amaneciera temprano para salir a mariscar, cuando llega el tiempo de llovizna", la aguja de tigre daba gran fortaleza, o el nqana de león hacía a los hombres "corajudos" para la pelea, etc. Asimismo, hasta hoy en día continúan vigentes una serie de "contagios" negativos vinculados a la trasgresión de los tabúes de menstruación y embarazo (TOLA, 2012; CITRO, 2003 y 2009; GÓMEZ, 2006 e 2011). Por último, ésta lógica del nawoGa sigue vigente en los cultos evangélicos aunque bajo otras modalidades (CITRO, 2012). En estos rituales, la intensidad de la música, la danza y la oración, se asocia a un estado de "gozo" entre los partícipes producido a la manera de un contagio que les permite sentir alegría, fortaleza y recuperarse de dolores o enfermedades.

En suma, frente a estas múltiples relaciones existenciales, la pregunta ontológica que emerge es si el cuerpo puede ser pensado sólo 
SILVIA CITRO y MARIANA GÓMEZ - Perspectivismo, fenomenología cultural...

como un gran diferenciador entre los seres, por presentar diversas fisonomías y habitus diferenciales, o si la experiencia corporal en el mundo también es el medio compartido por el cual nos conectamos con todos los otros existentes. Pues si optáramos por atribuir al "espíritu" (como algo distinto del cuerpo) estas últimas relaciones integradoras estaríamos negando la dimensión experiencial y encarnada que adquieren estos vínculos.

En relación a esta dificultad de utilizar separadamente las categorías de cuerpo y espíritu es pertinente precisar algunas de las categorías lingüísticas nativas. Como veremos, en la lengua toba no existe un término específico para "cuerpo", al menos no como se lo entiende en la tradición filosófica del racionalismo moderno y la medicina, en tanto totalidad material diferenciada de la razón, voluntad o alma del ser. Cabe recordar aquí la hipótesis de Leenhardt acerca de la inexistencia entre los canacos, así como en muchas sociedades tribales, de un término específico para designar a la totalidad del cuerpo. Al respecto, es conocida la anécdota que cita el autor (LEENHARDT, 1961, p. 227), acerca de la respuesta que le da un anciano canaco, aclarándole que aquello que los misioneros occidentales les habían "aportado" a los canacos no era "la noción de espíritu", como creía el misionero, sino la de "cuerpo".

Respecto a la supuesta noción de espíritu o alma, las categorías también son complejas. El término toba $/ k i$ ' $i$ tradicionalmente se ha traducido como el "alma-imagen" (WRIGHT, 1997 y 2008), y más recientemente, Tola $(2012$, p. 85$)$ sostiene que también refiere a "la imagen corporal" y a "la fuerza vital que la anima". No obstante, en nuestra etnografía y en los trabajos de Wright encontramos que el término se utiliza principalmente para referir a aquella dimensión de los humanos que puede escindirse del cuerpo durante el sueño, trasladándose a otros sitios, como también en algunos casos luego de la muerte, cuando el Iki'i de alguien recientemente fallecido o de un pioGonaq (chaman toba) poderoso, reaparece bajo diversas apariencias en las cercanías de su hogar. Así, el /ki'i habitualmente no es concebido como un alma inmaterial que actúa a la manera de un espíritu que rige todo acto de la vida humana, sino más bien como una extensión de la propia corporalidad que posee capacidades sensoriales y perceptivas 
SILVIA CITRO y MARIANA GÓMEZ - Perspectivismo, fenomenología cultural...

que se activarían especialmente en el sueño y la muerte ${ }^{11}$.

Por todo lo expuesto, sospechamos que esta utilización de las categorías de cuerpo y espíritu dentro del perspectivismo, más que reflejar una diferenciación clave del pensamiento y práctica "amerindia", estaría destinada a construir una relación de oposición simétrica e inversa a la ideología moderna (que sí utilizó estas categorías), continuando así con una tradición argumentativa típica del pensamiento estructuralista levi-straussiano ${ }^{12}$. Paradójicamente, si bien Viveiros de Castro desde una fina, novedosa y sofisticada reflexión plantea que las divisiones dicotómicas como naturaleza-cultura, mente-cuerpo, no son parte de las ontologías amerindias, éstas vuelven a ser reintroducidas cuando analiza esta experiencia. Esta es una de las contradicciones que más Ilaman la atención puesto que esta "reducción" a las propias categorías culturales del antropólogo sería uno de los "errores" más comunes en los que, según el autor, incurre la antropología13. Una posible explicación a la persistencia de estas categorías es que su uso responda a la necesidad de una comparación intercultural. No obstante, aún reconociendo esta intención y compartiendo con el autor que el objetivo de la antropología es "descolonizar" los pensamientos y poder re-mover/cuestionar nuestras categorías occidentales desde las filosofías indígenas ${ }^{14}$, consideramos que un abordaje sobre estas

\footnotetext{
${ }^{11}$ Cabe destacar que Tola brinda una definición más amplia del lki $i$ : "La capacidad de sentir sensaciones corporales se relaciona con la posesión de un lqui $i$ que otorga a humanos y a no humanos la capacidad de sentir, pensar, moverse y desplazarse" (TOLA, 2012, p. 85), y este lki'i se asentaría en el "corazón" (TOLA, 2012, p. 107). No obstante, consideramos que al menos en ese texto, no es del todo claro la relación entre los testimonios tobas allí citados y estas funciones rectoras generales que la autora asigna al $l k i$ 'i. Pero más allá de las funciones hoy asignadas al $l k i$ i por los tobas, lo que nos interesa destacar es que su misma traducción cuestionaría las tradicionales categorías modernas de cuerpo y espíritu, pues como la misma autora señala, el término haría referencia a "la corporalidad en su sentido de imagen percibida y de interioridad" o "fuerza vital" (TOLA, 2012, p. 85).

${ }^{12}$ Una crítica similar puede verse en Ramos (2012).

13 Por ejemplo, el autor sostiene que "describir ese multiverso donde toda diferencia es política, porque toda relación es social, como si fuera una versión ilusoria de nuestro propio universo, unificarlos a través de la reducción de la invención del primero a las convenciones del segundo, es elegir una forma demasiado simple -y políticamente mezquina- de relación entre ambos" (VIVEIROS DE CASTRO, 2010, p. 44).

${ }^{14}$ Según el autor, se trata de “... aproximarse al ideal de una antropología en cuanto ejercicio de descolonización permanente del pensamiento, y proponer otro modo de creación de conceptos distinto del modo filosófico" (VIVEIROS DE CASTRO, 2010, p. 24). No obstante, este esfuerzo descolonizador por constituir una "antropología indígena", retomando incluso a autores como Latour y Wagner, termina cediendo una vez más a los efectos de la lógica estructuralista, pues dicha antropología es reducida por Viveiros a una posición "simétrica e inversa" respecto de la "antropología occidental": "Perspectivismo interespecífico, multinaturalismo ontológico y alteridad caníbal forman entonces las tres vertientes de una alter-antropología indígena que es una transformación simétrica e inversa de la antropología occidental:
}

Espaço Ameríndio, Porto Alegre, v. 7, n. 1, p. 253-286, jan./jun. 2013. 
SILVIA CITRO y MARIANA GÓMEZ - Perspectivismo, fenomenología cultural...

cuestiones a partir de la experiencia de los amerindios, merecería ensayar un análisis que recurra a otras categorías más afines a esa experiencia.

En resumen, sostenemos que la utilización de las categorías de cuerpo y espíritu, poseen una fuerte impronta del racionalismo moderno y no parecen ser adecuadas para comprender las ontologías amerindias ni tampoco las occidentales contemporáneas y, por ello, proponemos sumar otros posibles interlocutores para este diálogo, tal es el caso de las categorías de Merleau-Ponty que nos permite hablar ya no de cuerpo y espíritu sino de los "seres en-el-mundo" y de la "carne" que los liga. Como veremos, este diálogo alternativo también nos permitirá apreciar que no todas son diferencias ontológicas entre amerindios y occidentales, ya que habría algunas similitudes en los modos en que experienciamos nuestras existencias encarnadas.

Cuarto diálogo existencial: sobre nuestros "seres-en-el mundo", la "carne" que nos integra y los "puntos de vista" que nos diferencian

El estudio de Leenhardt (1961) enfatizó la confrontación entre las diferentes formas en que las sociedades indígenas y las de la modernidad occidental concibieron la corporalidad de la persona. Así, el predominio de modelos holísticos o integradores de los vínculos entre cuerpo y mundo, en las primeras, y la escisión de ese vínculo junto con la preeminencia de la noción de cuerpo como "objeto" en las segundas, se transformaron en planteos que continúan vigentes en diferentes teorías. No obstante, nos interesa reevaluar críticamente este tipo de conceptualizaciones que enfatizan en las diferencias para preguntarnos si, a pesar de esta innegable diversidad, también existen elementos comunes que subyacen en la experiencia del vínculo cuerpo-mundo.

En su tesis de doctorado, Citro (2003) efectuó una relectura crítica de lo que denominamos la "hipótesis Leenhardt" sobre la diferencia radical de las corporalidades, apelando a un diálogo con las teorías filosóficas occidentales que confrontaron la supuesta veracidad

simétrica en el sentido de Latour, e inversa también en el sentido de la reverse anthropology de Wagner" (VIVEIROS DE CASTRO, 2010, p. 26). 
SILVIA CITRO y MARIANA GÓMEZ - Perspectivismo, fenomenología cultural...

ontológica y epistemológica del paradigma cartesiano. Allí planteamos que aquel holismo que Leenhardt describe como una particularidad de los canacos y, por extensión, de aquellos que aún denominaba como "primitivos", posee importantes similitudes con el holismo que MerleauPonty propone a través de sus nociones de "ser-en-el mundo" y "carne", en tanto experiencia fenomenológica del vínculo cuerpo-mundo común a todos los seres humanos.

Sintetizaremos primero las reflexiones de Leenhardt. El autor sostiene que los indígenas poseen simultáneamente una representación empírica, estética y mítica de su cuerpo y, para develar sus características, otorgará un lugar fundamental al estudio del lenguaje, los mitos y el ritual. Por ejemplo, como evidencia de los profundos vínculos entre cuerpo y naturaleza, señala que el léxico que designa las partes del cuerpo se corresponde con el del reino vegetal; asimismo, las correspondencias cuerpo-mundo se ilustrarían en la palabra karo, que designa "al elemento sustentador necesario a la realidad de diferentes seres y cosas", incluidos los humanos. En el lenguaje cotidiano de los tobas también existen términos que evidencian las analogías entre cuerpo y mundo. L'ok designa la piel de los seres humanos, el cuero de los animales y la cáscara de los frutos; lapat es su carne, y la pulpa de los frutos; lamo' es el tronco o el origen de algunas partes del cuerpo (de un brazo, lapik lamo', de la pierna, Ichi lamo), de un árbol y también de la comunidad (de sus antepasados, en la expresión lamoGoñi).

En el caso de Leenhardt concluye que en estas sociedades los mitos constituyen una realidad vivida y que estos vínculos no son meras figuraciones o analogías sino que implican una "identidad de estructura y una identidad sustancia" entre hombre y naturaleza:

El cuerpo humano está hecho de la misma sustancia que verdea el jade, que forma las frondosidades, que hincha de savia todo lo que vive, y estalla en los retoños y en las juventudes siempre renovadas. $Y$ porque se halla totalmente repleto de estas vibraciones del mundo, el cuerpo no se diferencia de él (LEENHARDT, 1961, p. 36).

El trabajo de Leenhardt fue objeto de numerosas críticas pues 
SILVIA CITRO y MARIANA GÓMEZ - Perspectivismo, fenomenología cultural...

tendía a una interpretación casi literal de los datos de sus informantes, sin problematizar la contextualización de los términos y la dimensión simbólica y polisémica que presenta todo lenguaje. Además, su idea de una "identidad de sustancia" estaba influida por el modelo de Lévy-Bruhl sobre la "participación" en la "mentalidad primitiva", también ampliamente criticado. Sin embargo, autores como Le Breton (1995) o incluso Csordas (1999) reconocen su sensibilidad para haber captado ciertas peculiaridades de la noción de cuerpo en estas sociedades que confrontaban la noción moderna. Lo que intentamos demostrar es que esta identidad y participación entre cuerpo y mundo que Leenhardt describió para los canacos podría haberse comprendido también desde una perspectiva fenomenológica cultural.

Para la fenomenología, así como no hay conciencia sin sujeto, tampoco la hay sin mundo y "el mundo está ahí previamente a cualquier análisis que yo pueda hacer del mismo" (CSORDAS, 1993, p. 10). Esta proposición redefine radicalmente la noción clásica de sujeto cartesiano, pues "el ser" pasa a considerarse como inseparable del mundo, es una relación, de ahí la noción de "ser-en-el mundo". Asimismo, nuestra relación práctica con el mundo no se daría en términos de un "yo pienso" sino de un "yo puedo" (CSORDAS, 1993, p. 154) pues se trataría de una experiencia previa al pensar que tenemos con el mundo y que se consuma a través del cuerpo propio (Leib). La noción de ser-en-el mundo implica el reconocimiento de una "dimensión preobjetiva o prerreflexiva" del ser, vehiculizada a través de la corporalidad irreductible a la res cogita y a la res extensa. El cuerpo media todas nuestras relaciones con el mundo, por ello, para Merleau-Ponty, no podría reducirse a un mero objeto, a algo que sólo "está" en el espacio y en el tiempo, sino que será quien los "habita" (CSORDAS, 1993, p. 156). Así, el cuerpo propio "tiene su mundo o comprende su mundo sin tener que pasar por unas representaciones, sin subordinarse a una 'función simbólica' u objetivante" (CSORDAS, 1993, p. 158). En términos de la "fenomenología cultural" de Csordas se trataría de reconocer que el embodiment o corporalidad es el "sustrato existencial de la cultura" y que "la experiencia corporizada es el punto de partida para analizar la participación humana en el mundo cultural" (CSORDAS, 1993, p. 136). Así, se busca "sintetizar la inmediatez de la experiencia corporal con la 
SILVIA CITRO y MARIANA GÓMEZ - Perspectivismo, fenomenología cultural...

multiplicidad de significaciones culturales en las cuales las personas están siempre e inevitablemente inmersas" (CSORDAS, 1999, p. 143).

Veamos brevemente el concepto de "carne" que aparece en las últimas obras de Merleau-Ponty (1970 e 1977). Esta noción permitiría superar la aparente paradoja que la experiencia de la corporalidad plantea, en tanto el cuerpo es a la vez sensible y sintiente, visible y vidente, es decir, puede convertirse en un cuerpo objetivo -pertenecer al orden del objeto a la manera de Descartes- pero también inevitablemente es un cuerpo fenoménico -aquel que ve y toca a las cosas y pertenece al orden del sujeto-. La "carne", entonces, hace referencia a este sintiente sensible que nos liga con el mundo, constituiría una especie de "principio encarnado", de todos los seres visibles y tangibles. Si bien este entramado de relaciones puede llegar a especificarse como un cuerpo, es sólo a condición de ser pensado, objetivado, escindido de su condición existencial de carne. Desde esta perspectiva, la imagen de Leenhardt de "un cuerpo repleto de las vibraciones del mundo", que se "confunde en un mismo flujo de vida", o los múltiples contagios o nawoGa que podrían afectar a una mujer toba menstruante, o el nqana de los antiguos cazadores tobas, pierden su exotismo y se acercan a la idea de Merleau-Ponty de que "el espesor del cuerpo, lejos de rivalizar con el del mundo, es, por el contrario, el único medio que tengo para ir hasta el corazón de las cosas, convirtiéndome en mundo y convirtiéndolas a ellas en carne" (MERLEAU-PONTY, 1970, p. 168).

Ahora bien, no se trata aquí solamente de postular una analogía entre estos autores sino de proponer una nueva mirada a partir de su confrontación. Aquella identidad y participación entre cuerpo y naturaleza que Leenhardt describe para los canacos podría ser comprendida como una de las formas culturales que puede adquirir la experiencia existencial de la carne. Así, no sería una experiencia exótica de consubstanciación ni tampoco una mera analogía de estructuras simbólicas o el resultado de una "unidad del espíritu" más o menos independientes de la experiencia. La diferencia se halla en que la ideología cultural de los indígenas canacos, los "chaqueños" u "amazónicos", tiende a visibilizar y valorar esta experiencia de la carne, mientras que la tradición cultural a la que pertenecía Leenhardt, en 
SILVIA CITRO y MARIANA GÓMEZ - Perspectivismo, fenomenología cultural...

cambio, la tendía a invisibilizar.

En resumen, en esta perspectiva la experiencia de la carne se convierte en un rasgo existencial de la vida humana; sin embargo, en la medida en que estos mundos son diferencialmente construidos en cada cultura y hasta las mismas prácticas cotidianas de los cuerpos son diferentes, aquella experiencia primaria de la carne adquiere modos disímiles y podrá ser representada de maneras diversas en las ideologías culturales, incluso ser enmascarada y negada.

Paradójicamente, si consideramos entonces que la experiencia de la carne posee una amplia extensión cultural en lo que refiere a las representaciones del cuerpo, podríamos invertir las proposiciones que asignan el exotismo a los Otros y señalar que es la concepción del cuerpo objeto la que resultaría exótica, en tanto marcadamente diferente a las de otras sociedades. En efecto, esta es la concepción que emerge como creación particular de una tradición sociocultural: la de la burguesía europea en su momento de consolidación, la cual intentaba borrar los lazos que testimoniaban los vínculos de la corporalidad con el mundo, vínculos que, sin embargo, se destacan en las representaciones de la persona de muchísimas otras sociedades, no sólo aborígenes, sino también, por ejemplo, en diferentes sistemas de creencias orientales, o incluso en las diversas culturas de la Europa previa a la modernidad (BAJTÍN, 1994; MELLOR y SCHILLING, 1997; PERROT, 2008).

En conclusión, releyendo las oposiciones del perspectivismo desde nuestra etnografía toba y la fenomenología cultural, consideramos que lo que solíamos identificar como "corporalidad" (que abarcaría desde la morfología corporal, fisiología, sensaciones, afectividades e "inclinaciones activas" encarnadas en gestos, palabras y movimientos hacia el mundo) además de "diferenciarnos" también serían el medio de "integrarnos" con los seres en el mundo: nos diferencia cuando es la sede de "puntos de vistas" distintos, pero nos integra cuando es "experiencia de la carne" compartida cotidianamente con el mundo. El proceso de objetivación reflexiva de mi propio cuerpo y de los otros existentes, es el que introduce una división, un corte en el espesor de la carne, creando la escisión entre el sujeto (el que ve, toca, percibe) y los otros (vistos-tocados, percibidos). Así, coincidimos con Viveiros de Castro cuando siguiendo a Deleuze señala que "el punto de vista crea al 
SILVIA CITRO y MARIANA GÓMEZ - Perspectivismo, fenomenología cultural...

sujeto (...), será sujeto quien se encuentre activado o "accionado" por el punto de vista" (VIVEIROS DE CASTRO, 2004, p. 57), pero no simplemente porque "el punto de vista está en cuerpos que son diferentes", sino porque es el acto reflexivo (encarnado, sí, en corporalidades diferentes) el que fractura la carne en un sujeto y otros existentes.

En suma, concordamos en que el perspectivismo de muchos pueblos amerindios se diferencia del naturalismo de la modernidad occidental por esta significación, extensión y valorización disímil otorgada al "espíritu", pero nos resulta difícil pensar que "el cuerpo" sea solo sede exclusiva de "diferencia" entre ellos y de "universalidad" entre nosotros. Más bien, proponemos pensar que tanto en "ellos" como en "nosotros", habría un sustrato experiencial común de la carne con el mundo, el cual al ser escindido u objetivado instaura las múltiples diferenciaciones identitarias, o posiciones de sujeto, entre los existentes, aunque, las maneras en que se construyan estas posiciones y los mismos existentes serán diferentes según las experiencias históricoculturales e incluso al interior de una sociedad, según las edades, el género y el poder.

Esto nos conduce a un último diálogo en torno a la imagen de los "amerindios" como personas que, siguiendo los escritos de Viveiros de Castro, parecieran estar subjetivados únicamente desde una única "ontología", la amerindia, como si ésta fuera el modelo experiencial básico, el sustrato original y esencial desde el cual los indígenas construyen y significan sus experiencias.

\section{Quinto diálogo: ¿sujetos amerindios vs sujetos de la modernidad...?}

Viveiros de Castro establece una serie de diferencias, ontológicamente radicales, entre los "amerindios" y los "sujetos modernos", que se encallan en la vieja oposición entre tradición y modernidad que, buena parte de la etnografía que sigue el lineamiento de las "áreas culturales", todavía insiste en utilizar. Sin embargo, no parece ocurrir lo mismo cuando Viveiros de Castro compara el perspectivismo con el postestructuralismo o, como lo denomina, el 
SILVIA CITRO y MARIANA GÓMEZ - Perspectivismo, fenomenología cultural...

"estructuralismo disidente de Deleuze" (VIVEIROS DE CASTRO, 2010, p. 24). Aquí, el perspectivismo sería un "socio insospechado" o "un precursor oscuro" de ciertos programas filosóficos contemporáneos que buscan instalarse fuera de las "dicotomías infernales de la modernidad" (VIVEIROS DE CASTRO, 2010, p. 25), y pone como máximo ejemplo al pensamiento de Deleuze y Guattari, de quienes toma numerosos ejemplos y citas para mostrar un parentesco múltiple entre las figuraciones rizomáticas y las que se podrían imaginar en el perspectivismo.

No obstante, concentrado en señalar este parentesco primigenio así como la "continuidad estructural" entre "las teorías antropológicas no triviales" y las "pragmáticas intelectuales" de los colectivos indígenas (VIVEIROS DE CASTRO, 2010, p. 17), el autor olvida mencionar las condiciones históricas que permiten leer las similitudes que comparten las "ontologías postestructuralistas" y aquellas amerindias. Desde hace décadas los modos de pensamiento en la filosofía y en las ciencias sociales y humanas reflexionan desde imaginarios más fluidos, procesuales e inacabados en torno a la relación individuo/sociedad. Frente a esta situación, las reflexiones que trae Viveiros de Castro podrían verse menos como un nuevo "descubrimiento" y más como una posibilidad de reflexión teórica situada históricamente: nuestras propias experiencias de persona, de ser persona en el mundo contemporáneo así como las narrativas del self que estructuran temporalmente el sentido en torno a "quienes somos", se están transformando. Este proceso nos abre la posibilidad de pensarnos tanto a nosotros mismos como a los "otros" desde modos de ser múltiples y complejos que acaban por acercanos. Así, las nociones de persona que podemos elaborar sobre los otros varían en función de los cambios en nuestras propias nociones y experiencias.

Pero volvamos a la caracterización de los amerindios. Al entregarse al juego de comparación y diferencia Viveiros de Castro radicaliza las distancias entre los "amerindios" y, prácticamente, el "resto del mundo". Como vimos, las razones que lo empujan a construir un "otro" radicalmente diferente al occidental podrían deberse a varias cuestiones: por un lado, la influencia de Lévi-Strauss (aunque cabe recordar que las comparaciones que éste hizo entre pensamiento salvaje y pensamiento 
SILVIA CITRO y MARIANA GÓMEZ - Perspectivismo, fenomenología cultural...

científico tenían otro sentido en su época); por otro, la idea de Deleuze de que no habría manera de trascender el dualismo epistemológico sino es pasando por él; finalmente, al pensar las diferencias entre unos y otros sujetos probablemente se apele a crear esquemas analíticos que lleven a resaltar las diferencias, prestando menos atención a las posibles similitudes.

Más allá de las intenciones que estimulan este esquema comparativo, nos interesa poner en discusión algunos de sus efectos: al radicalizar las diferencias entre amerindios y modernos Viveiros de Castro pasa por alto (o prefiere ignorar) el vínculo histórico y práctico de los "amerindios" con esa "modernidad". Tal como son descriptos en Metáforas Canibales, serían sujetos que viven aislados o resguardados en sus propias ontologías, cosificados, el prototipo de un otro impermeable a otras ontologías, personas inmersas en otros juegos de lenguaje, pensamientos y prácticas. Sin embargo, en nuestras etnografías hallamos que estas relaciones problemáticas con la "modernidad" constituyen uno de los antagonismos centrales de las subjetividades indígenas. En diversos contextos locales indígenas poscoloniales, el advenimiento de la ideología de la modernidad ocurrió durante el siglo XIX y el XX a través de la expansión de las misiones, la conversión religiosa y la economía de mercado. Estas dinámicas afectaron, entre muchas otras cosas, las dimensiones dividuales de la "persona", ya que en la mayoría de los grupos indígenas existen una serie de obligaciones e intercambios basados en la reciprocidad (LIPUMA, 1998, p. 199; KNAUFT; 1997, entre otros). Diversos aspectos de la modernidad permiten que las dimensiones individuales de las personas se tornen más visibles y legítimas aparejando nuevas tensiones entre las personas, los grupos y las generaciones. En tales procesos es imposible que los indígenas no transformen sus subjetividades, poniendo en tensión las prácticas de socialización vigentes con las nuevas expectativas, deseos, posibilidades e imaginarios, implicándose en todo ello "reformas corporales" graduales pero constantes (COMAROFF y COMAROFF, 1991) o, en otros términos, la transformación de los habitus, las corporalidades y la construcción de nuevas posiciones identitarias. Los indígenas son, como cualquier persona, sujetos híbridos que operan en su vida social a partir de la 
SILVIA CITRO y MARIANA GÓMEZ - Perspectivismo, fenomenología cultural...

integración de modos de ser forjados en circunstancias históricas y culturales pues, las ontologías amerindias coexisten, se imbrican, yuxtaponen y confrontan con aspectos ontológicos e ideológicos de las modernidades periféricas donde los indígenas desarrollan sus vidas: integrándose, sintetizándose y confrontándose simultáneamente en/con los aspectos de unas y otras.

Considerando lo anterior nos preguntamos si no sería más provechoso para nuestros análisis partir de la idea de que los indígenas construyen sus experiencias desde diferentes habitus o corporalidades que coexisten (en una misma persona, a la manera de registros distintos) antes que seguir concibiendo la idea de que están inmersos en una única ontología actuada por un único habitus, tal como si el perspectivismo fuera la ontología esencial, primaria o determinante sobre la cual se superpondrían, a la manera de residuos ontológicos, el resto de las prácticas forjadas en contacto con otras ontologías, como las modernas o posmodernas. Sería más enriquecedor intentar una lectura dialéctica sobre la interacción entre "modos de ser" diversos que una misma persona indígena sostiene como parte de los distintos contextos donde interactúa y se forjan sus posiciones de sujeto y sus distintas identidades.

Consideramos que esta idea de una ontología primaria o determinante también se aprecia en el caso de los estudios sobre los tobas, especialmente en el último trabajo de Tola (2012), inspirado justamente en el perspectivismo y los trabajos de Descola. Por ejemplo, cuando la autora discute con Gordillo respecto de la propia auto imagen de los tobas como "pobres" o choGodaq sostiene:

no creemos que el fundamento de esta noción derive del proceso histórico y de las relaciones interétnicas de dominación, antes bien debería buscarse en las relaciones que los qom entablan con las personas nohumanas (...) ya que éstas son percibidas como detentadoras de un mayor poder que el de los humanos (TOLA, 2012, p. 103).

En esta misma línea de argumentación, Tola también propone demostrar que el "el cuerpo no es, desde la óptica toba (...) el lugar de aplicación de una "microfísica de la dominación", sino "más bien el 
SILVIA CITRO y MARIANA GÓMEZ - Perspectivismo, fenomenología cultural...

vector de la producción misma de la vida social" (TOLA, 2012, p. 3738). Así, el análisis "enfatiza en las relaciones entre las persona humanas así como en las que tienen lugar entre éstas y los seres nohumanos" (TOLA, 2012, p. 36), y esto último se convierte en el modelo relacional del cual se "derivan", incluso, la lógica que estructuraría las relaciones de poder con los blancos (TOLA, 2012, p. 103). De este modo, sostiene que la autopercepción como "pobres" de los tobas, "va más allá de las condiciones de vida de los qom y se relaciona con la reproducción de un ethos que exalta el autocontrol y la mesura" (TOLA, 2012 , p. 103). El problema que advertimos es que en esta intención de "ir más allá", a veces no queda del todo claro en el análisis, como este ethos y sus concepciones ontológicas interactúan con las condiciones de vida materiales y los procesos de dominación. Se promueve así una perspectiva que, al remarcar esta escisión entre lo material y lo ideal, en cierta forma termina reproduciendo la división dualista cuerpo-espíritu de la modernidad.

En contraposición a esta perspectiva, nosotras insistimos en señalar que las relaciones y experiencias sociales no tendrían "fundamentos" primarios ni esenciales (esto sería, en todo caso, una "creencia" de orden epistemológico dentro de la disciplina), porque se generan contextual e históricamente. Tampoco creemos que otorgarle importancia a unos "fundamentos" deba conducir a restarle importancia a los otros: éstos coexisten y dependerá de la perspectiva teórica del o la antropóloga a cuáles se les dará más prioridad (aunque no todos los marcos teóricos tienen la misma capacidad de explicación y comprensión), así también como de los contextos de interacción que está etnografiando. En este sentido, podríamos pensar que será más probable encontrar "dominación" y "microfísicas de poder" en ciertas prácticas, como un ritual evangélico o el trabajo en la cosecha, y "ontologías" con fundamentos más o menos inalterables en otros, como en la mitología y las prácticas chamánicas. En suma, creemos que el "fenómeno" más rico para analizar y comprender, para el caso de cualquier experiencia, no son unos u otros "fundamentos" por separado, sino la coexistencia dialéctica de ambos -a veces armoniosa, a veces antagónica- como resultado de experiencias históricas y culturales que se entrecruzaron, produciendo nuevas síntesis en las prácticas de las 
SILVIA CITRO y MARIANA GÓMEZ - Perspectivismo, fenomenología cultural...

personas -sean o no indígenas-.

Por último, otro elemento a discutir dentro del perspectivismo, es que la cosificación del "amerindio" que en él se advierte, también ignora que las prácticas y reivindicaciones sustentadas en ontologías amerindias han pasado a formar parte de las políticas étnicas en América Latina. Si consideramos el heterogéneo estado actual de los movimientos indígenas en nuestro continente, deberíamos reconocer que el privilegio de practicar y vivir inmerso en otra ontología depende de un escenario de luchas políticas que remiten, por ejemplo, a enfrentamientos sobre el uso y la propiedad de la tierra, puesto que para los indígenas se trata de crear el mundo en otros términos, implicándose profundas desavenencias con la ontología y epistemología del actual capitalismo extractivista. Por eso, como afirma Marisol de la Cadena, las ontologías indígenas están agazapadas en las "sombras" de la política actual (DE LA CADENA, 2008, p. 108). Sin embargo, Viveiros de Castro en pleno siglo XXI parece ignorar que las otras ontologías indígenas hoy también son un arma de lucha desplegada en complejos escenarios o que el "amerindio" además de "persona" también es un "sujeto político". "Política" y "persona" parecen no congeniar en el imaginario del autor, o al menos hacerlo de una manera muy particular. En este sentido, Ilama la atención la posición de Viveiros de Castro cuando plantea que el "multiculturalismo" y el "multinaturalismo" pueden ser comparadas como dos políticas ontológicas diferentes, donde una, en términos estructuralistas, representaría la inversión de la otra. No obstante, pensamos que el "multiculturalismo" más que una mera ontología es una forma de gubernamentalidad (es decir, un fenómeno de otro orden y nivel) cuyo principal ejercicio es el control político de la "diversidad cultural" bajo el discurso de albergar y permitir el ejercicio de la diferencia -siempre y cuando no se cuestione radicalmente la política neoliberal-. Siguiendo este razonamiento, y aún si nos permitimos suponer con Viveiros de Castro que son dos políticas ontológicas diferentes, entre "multiculturalismo" y "multinaturalismo" existiría, antes que nada, una relación de antagonismo y hegemonía política y no meramente una "inversión" lógica (o en todo caso sería una inversión que en términos históricos se manifiesta antagónicamente). En efecto, dentro del contexto histórico actual, el multiculturalismo sería 
SILVIA CITRO y MARIANA GÓMEZ - Perspectivismo, fenomenología cultural...

una política que intenta neutralizar los efectos (la radicalidad política) del multinaturalismo que subyace a las ontologías indígenas:

La cultura, la etnicidad, el multiculturalismo pueden dar cabida a la diferencia, pero no conjuran (hasta el momento) la alteridad radical de las prácticas albergadas en los muchos mundos que evocan los zapatistas y que habitan las sombras de la política (DE LA CADENA, 2008, p. 108).

\section{Reflexiones finales}

A lo largo de este trabajo hemos intentado un diálogo entre ciertos planteos del perspectivismo sobre la persona y la corporalidad con otras teorías y experiencias etnográficas con grupos indígenas de las tierras bajas sudamericanas. Fundamentalmente, nuestra discusión se centró en dos planteos: por un lado, el uso de las categorías de cuerpo y espíritu como uno de los ejes centrales para comprender la manera en se estructuraría el perspectivismo amerindio. Aquí, llamamos la atención sobre una caracterización que, consideramos, descuida el análisis de las connotaciones que estos términos poseen en la propia filosofía racionalista de la modernidad así como en las diversas culturas amerindias. En este sentido, el examen de los alcances semánticos de cada término y las superposiciones que por momentos involucran, nos condujo a intentar un diálogo con otras categorías que vislumbramos cómo menos problemáticas para pensar la existencia de humanos y no humanos, tal es el caso de la noción fenomenológica de carne. Por otro lado, analizamos críticamente como dicha estructura dual era colocada en una relación simétrica e inversa a las ideologías de la modernidad, postulando así una generalización que tiende a abstraer la ontología de las relaciones históricas de los grupos indígenas con los procesos económicos, políticos y culturales ligados a la modernidadposmodernidad. En suma, si bien reconocemos que el perspectivismo ha contribuido a destacar y problematizar algunas especificidades de las filosofías o modo de pensamiento de los indígenas de las tierras bajas sudamericanos, hemos planteado también nuestras dudas respecto a las ventajas de una teoría que privilegia un único modelo ontológico para 
SILVIA CITRO y MARIANA GÓMEZ - Perspectivismo, fenomenología cultural...

reflexionar sobre las prácticas indígenas, más aún si consideramos que Viveiros de Castro se propone como parte de su programa una descolonización profunda del pensamiento antropológico: ¿es posible lograr esto si el proyecto pasa por volver a reinstalar a los amerindios nuevamente como "nuestros otros" radicalmente diferentes, lo que ellos no son, y lo que no somos nosotros...?

Finalmente, creemos que se puede ir más allá del mero ejercicio de pensamiento a nivel estructural cuando se asume que los enfrentamientos políticos son ontológicos -y viceversa- o cuando se considera que la politización de las ontologías indígenas son recursos claves de las políticas étnicas que vienen construyendo los grupos indígenas.

\section{Bibliografía}

BAJTÍN, Mijail. La cultura popular en la Edad Media y en el Renacimiento: el contexto de Francois Rabelais (1930). Buenos Aires: Alianza, 1994.

BORMIDA, Marcelo. Mito y Cultura. Runa, Buenos Aires, v. 12, p. 9-52, 1969.

BOURDIEU, Pierre. El sentido práctico. Madrid: Taurus, 1991.

CARDIN, Lorena. La vigencia del don entre los toba formoseños: el caso de la Colonia Aborigen La Primavera. Tesis de Licenciatura en Antropología, Facultad de Filosofía y Letras, UBA, 2007.

CERIANI CERNADAS, Cesar. Nuestros hermanos Lamanitas: indios y fronteras en la imaginación mormona. Buenos Aires: Biblos, 2008.

CITRO, Silvia. De las representaciones a las prácticas: la corporalidad en la vida cotidiana, Acta Americana, Washington, v. 10, n. 1, p. 93-112, 2002.

Cuerpos significantes: una etnografía dialéctica con los toba takshik. Tesis de Doctorado. Facultad de Filosofía y Letras. Universidad de Buenos Aires, 2003.

Creando una mujer: ritual de iniciación femenina y matriz simbólica de los géneros entre los toba takshik. In: HIRSCH, Silvia (Org.). Mujeres indígenas en la Argentina: cuerpo, trabajo y poder. Buenos Aires: Biblos, 2008. p. 12-36.

Cuerpos significantes: travesías de una etnografía dialéctica. Buenos Aires: Biblos, 2009. 
SILVIA CITRO y MARIANA GÓMEZ - Perspectivismo, fenomenología cultural...

93, 2012.

La eficacia ritual en y desde los cuerpos. Ilha, Florianópolis, v. 13, v. 1, p. 61-

CITRO, Silvia; CERLETTI, Adriana. Aboriginal dances were always in rings... music and dance as a sign of identity in the Argentine Chaco. Yearbook for Traditional Music, Paris, v. 41, p. 138-165, 2009.

COMAROFF, John; COMAROFF, Jean. Bodily Reform as Historical Practice. In: 1991. p. 69-91.

Ethnography and the Historical Imagination. Westview Press: Oxford,

CORDEU, Edgardo; SIFFREDI, Alejandra. De la algarroba al algodón: movimientos milenaristas del Chaco Argentino. Buenos Aires: Juárez Editor, 1971.

CSORDAS, Thomas. Somatic Modes of Attention. Cultural Anthropology, Durhan, v. 8, n. 2, p. 135-156, 1993.

Embodiment and Cultural Phenomenology. In: WEISS, Gail; HABER, Honi

(Org.). Perspectives on Embodiment. New York: Routledge, 1999. p. 143-162.

DE LA CADENA, Marisol. Asumir la política indígena en sus propios términos requiere un análisis más allá de lo político. Crónicas Urbanas, Lisboa, v. 3, p. 98-116, 2008.

DELEUZE, Gilles; GUATTARI, Félix. Qu'est-ce que la philophie? Paris: Minuit, 1991.

DESCOLA, Philippe. Construyendo naturalezas: ecología simbólica y práctica social. In: DESCOLA, Philippe; PALSSON, Gisli (Org.). Naturaleza y sociedad: perspectivas antropológicas. Madrid: Siglo XXI editores, 2001. p. 101- 123.

DE SOUSA SANTOS, Boaventura. Una epistemología del Sur. Buenos Aires: CLACSO, 2009.

ELIAS, Norbert. El proceso de la civilización: investigaciones sociogenéticas y psicogenéticas. Buenos Aires: Fondo de Cultura Económica, 1993.

GARCÍA, Miguel Ángel. Paisajes sonoros de un mundo coherente: prácticas musicales y religión en la sociedad wichí. Buenos Aires: Instituto Nacional de Musicología Carlos Vega, 2005.

GÓMEZ, Mariana. Representaciones y prácticas en torno a la menstruación y menarca entre mujeres tobas: entre la salud de las mujeres y la construcción social del género femenino. Papeles de Trabajo, Buenos Aires, v. 14, p. 9-51, 2006.

Las mujeres en el monte: las formas de vinculación con el monte que practican las mujeres tobas (qom). Revista Colombiana de Antropología, Bogotá, v. 44, n. 2, p. 
SILVIA CITRO y MARIANA GÓMEZ - Perspectivismo, fenomenología cultural...

373-408, 2008a.

El cuerpo por asalto: la amenaza de la violencia sexual entre las mujeres tobas del oeste de Formosa. In: HIRSCH, Silvia (Org.). Mujeres indígenas en la Argentina: cuerpo, trabajo y poder. Buenos Aires: Biblos, 2008b. p. 79-116.

Las mujeres también luchan: reflexiones sobre la violencia interpersonal femenina entre las mujeres tobas y su vínculo con la construcción social del género en el pasado. Trabajo presentado en el I Coloquio de Investigación: Género y Ciencias Sociales. Instituto Interdisciplinario de Género (FFyL, UBA) y DAAD (Alemania). Buenos Aires, 6 y 7 de octubre, 2009.

De género, mitos y rituales: notas críticas sobre los estudios de género en Amazonía. Publicar en Antropología, Buenos Aires , v. 8, n. 9, p. 145-169, 2010.

De Recolectoras a Artesanas: género, espacialidades e identidades entre las mujeres tobas. Tesis de Doctorado. Facultad de Filosofía y Letras, UBA, 2011.

GORDILLO, Gastón. Cazadores-recolectores y cosecheros: subordinación al capital y reproducción social entre los tobas del oeste de Formosa. In: TRINCHERO, Hugo; PICCININI, Daniel; GORDILLO, Gastón (Org.). Capitalismo y grupos indígenas en el Chaco Centro-Occidental (Salta y Formosa). Buenos Aires: Centro Editor de América Latina, 1992, p. 13-191.

La presión de los más pobres: reciprocidad, diferenciación social y conflicto entre los tobas del oeste de Formosa. Cuadernos del Instituto Nacional de Antropología y Pensamiento Latinoamericano, Buenos Aires, v. 15, p. 53-82, 1994.

Locations of hegemony: the making or places in the Toba's struggle for La Comuna, 1989-1999. American Anthropologist, Washington, v. 104, n. 1, p. 262-277, 2002.

Landscapes of devils: tensions of places and memory in the Argentinean Chaco. Duke: University Press, 2004.

2006.

En el Gran Chaco: Antropologías e Historias. Buenos Aires: Prometeo Libros,

GUALDIERI, Beatriz et al. Lengua, cultura e historia mocoví en Santa Fe. Buenos Aires: Universidad de Buenos Aires, 2006.

HERMITTE, Esther et al. Estudio sobre la situación de los indígenas del Chaco y políticas para su integración a la sociedad nacional. Posadas: Editorial de la Universidad Nacional de Misiones, 1995.

KNAUFT, Bruce. Gender Identity, Political Economy and Modernity in Melanesia and Amazonia. Journal of the Royal Anthropological Institute, Londres, v. 3, n. 2, p. 233-259, 1997. 
SILVIA CITRO y MARIANA GÓMEZ - Perspectivismo, fenomenología cultural...

LAGOS, Marcelo. La cuestión indígena en el Estado y la Sociedad Nacional: Gran Chaco 1870-1920. San Salvador de Jujuy: Universidad Nacional de Jujuy, 2000.

LE BRETON, David. Antropología del Cuerpo y Modernidad. Buenos Aires: Nueva Visión, 1995.

LEENHARDT, Maurice. Do Kamo. Buenos Aires: Eudeba, 1961.

LÉVI-STRAUSS, Claude. Mitológicas: lo crudo y lo cocido I. México: Fondo de Cultura Económica, 1986.

LIPUMA, Edward. Modernity and forms of personhood in Melanesia. In: LAMBEK, Michael; STRATHERN, Andrew (Org.). Bodies and persons: comparative perspectives from Africa and Melanesia. Cambridge: Cambridge University Press, 1998. p. 53-79.

MELLOR, Philip; SCHILLING, Chris. Re-Formed Bodies. In: the Body: religion, community, and modernity. London: Sage, 1997. p. 35-63. Re-Forming

MENEZES BASTOS, Rafael. Music in the Indigenous Societies of Lowland South America: State of the Art. Mana, Rio de Janeiro, v. 13, n. 2, p. 293-326, 2007.

MENDOZA, Marcela. Band Mobility and Leadership among the Western Toba Hunter-Gatherers of Gran Chaco in Argentina. New York: The Edwin Mellen Press, 2002.

MERLEAU-PONTY, Maurice. Lo visible y lo invisible. Barcelona: Seix Barral, 1970.

El Ojo y el Espíritu. Buenos Aires: Paidós, 1977.

Fenomenología de la percepción. Barcelona: Planeta Agostini, 1985.

MILLER, Elmer. Armonía y Disonancia en una sociedad: los tobas argentinos. México: Siglo Veintiuno, 1979.

PERAZZI, Pablo. Hermeneútica de la barbarie: una historia de la antropología en Buenos Aires, 1935-1966. Buenos Aires: Sociedad Argentina de Antropología, 2003.

PERROT, Michelle. Mi historia de las mujeres. Buenos Aires: Fondo de Cultura Económica, 2008.

RAMOS, Alcida Rita. The politics of Perspectivism. Annual Review of Anthropology, Londres, v. 41, p. 481-494, 2012.

SEEGER, Anthony; DA MATTA, Roberto; VIVEIROS DE CASTRO, Eduardo. A construcao da Pessoa nas sociedades indígenas brasileiras. Boletim do Museu Nacional, Rio de Janeiro, v. 32, p. 2-30, 1979. 
SILVIA CITRO y MARIANA GÓMEZ - Perspectivismo, fenomenología cultural...

TISCORNIA, Samantha; GOLIER, C. Hermeneútica y fenomenología: exposición crítica del método fenomenológico de Marcelo Bórmida, Etnía, v. 31, p. 20-38, 1984.

TOLA, Florencia. Constitución del cuerpo femenino entre los tobas (qom) del este formoseño. In: HIRSCH, Silvia (Org.). Mujeres Indígenas en la Argentina: cuerpo, trabajo y poder. Buenos Aires: Biblos, 2008. p. 59-78.

Yo no estoy solo en mi cuerpo: cuerpos-personas múltiples entre los tobas del Chaco argentino. Buenos Aires: Biblos, 2012.

TRINCHERO, Hugo; PICCININI, Daniel; GORDILLO, Gastón (Org.). Capitalismo y grupos indígenas en el Chaco Centro-Occidental (Salta y Formosa). Buenos Aires: Centro Editor de América Latina, 1992.

VIVEIROS DE CASTRO, Eduardo. Alguns aspectos da afinidade no Dravidianato Amazônico. In: VIVEIROS DE CASTRO, Eduardo; CARNEIRO DA CUNHA, Manoela (Org.). Etnología e história indígena. São Paulo: FAPESP, 1993. p. 149-210.

Perspectivismo y multinaturalismo en la América Indígena. In: SURRALLÉS, A.; GARCÍA HIERRO, P. (Org.). Tierra adentro: territorio indígena y percepción del entorno. Buenos Aires: IWGIA, 2004. p. 37-80.

Metafísicas Caníbales: Líneas de Antropología Postestructural. Buenos Aires: Conocimiento, 2010.

WRIGHT, Pablo. Being-in-the-dream: postcolonial explorations in Toba Ontology. Ph.D. dissertation, Department of Anthropology, Temple University, 1997.

Ser-en-el-sueño: crónicas de historia y vida toba. Buenos Aires: Biblos, 2008.

Espaço Ameríndio, Porto Alegre, v. 7, n. 1, p. 253-286, jan./jun. 2013. 